\title{
Thermodynamic modeling of the rare elements behavior during the dissolution of heat-resistant nickel alloys waste in mineral acids
}

\author{
(C) Andrey S. Russkih, ${ }^{+}$Sergey A. Krasikov, ${ }^{*}$ \\ Ekaterina M. Zhilina, and Sergey A. Podkorytov \\ Laboratory of the High Enthropy Alloys. Institute of Metallurgy UB RAS. Amundsena St., 101. Ekaterinburg, \\ 620016. Russia. Phone:+7 (343) 232-91-22.E-mail: russkih_a_s@mail.ru
}

\begin{abstract}
* Supervising author; ${ }^{+}$Corresponding author Keywords: thermodynamic modeling, heat resistant nickel alloy, rare elements, mineral acids, dissolution.
\end{abstract}

\begin{abstract}
This work is aimed at studying the possibility of heat-resistant alloys waste processing, in particular, to determine the distribution of elements of a heat-resistant nickel alloy in solutions of mineral acids. The aim of the work was to predict the behavior of alloy components using the method of thermodynamic analysis. The research results can serve as a scientific basis for the development of promising technologies for the processing of metal wastes of heat-resistant alloys, allowing the extraction and separation of valuable rare and non-ferrous metals. Thermodynamic modeling of the interaction for the heat-resistant nickel alloy containing refractory rare metals with hydrochloric, sulfuric and nitric acids was carried out within a temperature range of $20-100{ }^{\circ} \mathrm{C}$ and concentration from 50 to $150 \mathrm{~g} / \mathrm{dm}^{3}$ under a pressure of $1 \mathrm{~atm}$. According to the results of calculations, it was revealed that nickel transfers into sludge, both in the form of a metal and in the form of a $\mathrm{Ni}_{4} \mathrm{~W}$ compound. A temperature growth of more than $60{ }^{\circ} \mathrm{C}$ and an acid concentration from 50 to $150 \mathrm{~g} / \mathrm{dm}^{3}$ do not affect predominant distribution of tantalum and niobium pentoxides into the slurry and contributes to the transition to a solution of non-ferrous metals. The obtained data of thermodynamic modeling were confirmed in experiments on the anodic dissolution of the alloy in sulfate solutions. According to the results of X-ray phase analysis of sludge, it was found that the highest intensity of the diffractogram peaks corresponded to a solid solution of tungsten in nickel. The oxide phases of tantalum were also detected. In the electrolyte solution transferred, mainly Re, Co, Cr. Thus, it was shown the possibility of using the method of thermodynamic modeling to predict the behavior of elements in the processing of waste heat-resistant nickel alloys.
\end{abstract}

\section{References}

[1] A.A. Palant, V.A. Pavlovsky. Physico-chemical and technological bases of electrochemical processing of tungsten metal waste. Metal technology. 2003. No.11. P.3-7.

[2] A.G. Kasikov, A.M. Petrova. Rhenium recycling from waste heat-resistant and special alloys. Metal technology. 2010. No.2. P.2-12.

[3] A.A. Palant, V.A. Bryukvin, O.M. Gracheva. Electrochemical processing of tungsten-rhenium alloy wastes under the action of alternating current of industrial frequency. Electrometallurgy. 2005. No.5. P.31-34.

[4] A.A. Palant, O.M. Levchuk, V.A. Bryukvin et al. Complex electrochemical processing of metal wastes of rhenium-containing heat-resistant nickel alloy in sulfuric electrolytes. Electrometallurgy. 2010. No.7. P.29-33.

[5] HSC Chemistry for Windows. Chemical Reaction and Equilibrium Software wthis extensive Thermochemical Database. Outotec Reseach Oy Information Services, Finland. URL:

[6] http://www.outotec.com/hsc

[7] E.M. Zhilina, S.A. Krasikov, S.N. Agafonov et al. Thermodynamic and Kinetic Features of the CoAluminothermic Reduction of Titanium and Zirconium from Oxides. Butlerov Communications. 2016. Vol.45. No.1. P.130-135. DOI: 10.37952/ROI-jbc-01/16-45-1-130

[8] E.M. Zhilina, S.N. Agafonov, A.S. Russkikh et al. Interaction of aluminum with a multicomponent oxide system containing zirconium, titanium, silicon, iron. Butlerov Communications. 2017. Vol.51. No.7. P.55-60. DOI: 10.37952/ROI-jbc-01/17-51-7-55 
[9] E.M. Zhilina, S.A. Krasikov, A.S. Gordeeva et al. Investigation of the possibility of obtaining rare-metal sludge from waste heat-resistant nickel alloys. Butlerov Communications. 2018. Vol.55. No.9. P.82-85. DOI: 10.37952/ROI-jbc-01/18-55-9-82

[10] S.A. Krasikov, A.A. Ponomarenko, S.N. Agafonov, T.I. Chupakhina, G.V. Bazuev, M.A. Ponomareva. Recycling of waste heat-resistant alloys to produce intermediate for the manufacture of rhenium catalysts. Materials of the 2nd Russian conference with international participation "New approaches in chemical technology of mineral raw materials. The use of extraction and sorption. St. Petersburg 03-06 June 2013, Part 2, Apatity: Ed. Kola Scientific Center of RAS. 2013. P.142-143. 